\title{
Article \\ Modelling the Transition towards a Carbon-Neutral Electricity System-Investment Decisions and Heterogeneity
}

\author{
Jinxi Yang * $\mathbb{D}$, Christian Azar $(\mathbb{D}$ and Kristian Lindgren $(\mathbb{D}$ \\ Department of Space, Earth and Environment, Chalmers University of Technology, \\ SE-412 96 Gothenburg, Sweden; christian.azar@chalmers.se (C.A.); kristian.lindgren@chalmers.se (K.L.) \\ * Correspondence: jinxi.yang@chalmers.se
}

check for

updates

Citation: Yang, J.; Azar, C.; Lindgren, K. Modelling the Transition towards a Carbon-Neutral Electricity

System-Investment Decisions and Heterogeneity. Energies 2022, 15, 84 .

https://doi.org/10.3390/en15010084

Academic Editors:

Panagiotis Fragkos and

Pelopidas Siskos

Received: 25 October 2021

Accepted: 15 December 2021

Published: 23 December 2021

Publisher's Note: MDPI stays neutral with regard to jurisdictional claims in published maps and institutional affiliations.

Copyright: (c) 2021 by the authors. Licensee MDPI, Basel, Switzerland. This article is an open access article distributed under the terms and conditions of the Creative Commons Attribution (CC BY) license (https:// creativecommons.org/licenses/by/ $4.0 /)$.

\begin{abstract}
To achieve the climate goals of the Paris Agreement, greenhouse gas emissions from the electricity sector must be substantially reduced. We develop an agent-based model of the electricity system with heterogeneous agents who invest in power generating capacity under uncertainty. The heterogeneity is characterised by the hurdle rates the agents employ (to manage risk) and by their expectations of the future carbon prices. We analyse the impact of the heterogeneity on the transition to a low carbon electricity system. Results show that under an increasing $\mathrm{CO}_{2}$ tax scenario, the agents start investing heavily in wind, followed by nuclear and to some extent in natural gas fired power plants both with and without carbon capture and storage as well as biogas fired power plants. However, the degree to which different technologies are used depend strongly on the carbon tax expectations and the hurdle rate employed by the agents. Comparing to the case with homogeneous agents, the introduction of heterogeneity among the agents leads to a faster $\mathrm{CO}_{2}$ reduction. We also estimate the so called "cannibalisation effect" for wind and find that the absolute value of wind does not drop in response to higher deployment levels, but the relative value does decline.
\end{abstract}

Keywords: agent-based modelling; low carbon electricity system; investment decisions; heterogeneous agents; value factor of wind

\section{Introduction}

The Paris Agreement [1] implies that emissions may have to drop by as much as half over the next decade or two, and then reach approximately zero by the middle of the century [2,3] (The required rate of emission reduction depends on the climate sensitivity, the temperature target as well as the assumed pathway towards the ultimate target (i.e., the degree to which an overshoot is accepted or not [3]).

In order to achieve the climate objectives of the Paris Agreement, the power sector must undergo a rapid transition towards carbon-neutral energy technologies over the next couple of decades. Since investments in power plants today will shape the power system for decades to come, understanding investment decisions in the context of current climate ambitions is critical.

Understanding how this transition may take place requires energy-system models. Typically, these are optimisation models that assume perfect foresight and one central (rational) optimiser making decisions for the entire economy in pursuit of the least-cost path that meets climate or emission constraints [4-8].

We believe such models can provide important insights. However, there is also a need to analyse the transition through a perspective that more closely resembles the workings of a real economy, where companies compete against one another and make investments in the power sector based on their risk aversion and capital costs as well as the available information, including expected electricity, fuel and carbon prices. An agent-based model $(\mathrm{ABM})$ may provide such a perspective and relevant insights into complex energy-transition dynamics [9]. 
An ABM consists of a system of interacting agents, and it includes an explicit description of agents' decisions based on their (possibly limited) information about the system (including other agents). An ABM is often referred to as a simulation technique that enables modelling individual, heterogeneous and autonomous agents, where each agent individually assesses its situation and makes decisions on the basis of a set of rules [10]. In the context of the energy-system transition, ABMs can provide a complementary perspective to optimisation models.

Several ABMs have been used to study the capacity investments in the energy system under climate policies. For instance, Chappin, et al. [11] have developed an ABM-the Energy Modelling Laboratory (EMLab) - and modelled power companies' investments in generation capacity under climate policy. Agents in EMLab use past years data to forecast future fuel, electricity and $\mathrm{CO}_{2}$ prices, and agents' heterogeneity is represented by the length of years that an agent used for making the forecast. Jonson et al. [12] compared the capacity investments from an ABM with a corresponding optimization model, and found results were similar, but that due to the limited foresight of the agent in the ABM, there are underinvestments and overinvestments capacity in the ABM compared to the results from the optimisation model. Kraan, et al. [13] studied energy transition pathways by simulating decision-making in investing in new power plants. Heterogeneity in this study is represented by the agents' discount rates (which range from $4 \%$ to $20 \%$ in this study). The results show that under a constant carbon-price scenario, the capacity mix of the system stays the same over time when agents use the same discount rate (homogeneous agents), while in the heterogenous agents case, a range of possible transition pathways are taken. Barazza and Strachan [14] explored the impacts of agent heterogeneity on investment decisions about power generation technologies. Heterogeneity in this study is represented by the agent's aim, technology preference, foresight and costs of capital. They modelled the transitions of the UK, German, and Italian electricity sectors and illustrated the impact of agents' heterogeneous characteristics on the number of investments made, which may accelerate or hamper efforts to reach decarbonisation goals.

These ABM studies find that at the aggregated system level, results relating to the overall capacity mix and electricity output differ from cases where models only include homogeneous agents or a central optimiser. This demonstrates that there may be significant value to considering the fact that agents in real world electricity systems tend to be heterogeneous, and therefore, it may be beneficial to use ABM with heterogeneous characteristics for exploring the energy transition.

In our previous ABM study [12], we identified how a bottom up analysis of companies' investment decisions may provide a different perspective or results compared to an optimisation modelling approach, and in that way having a model that more directly reflects decisions on liberalised electricity markets in the real world (where there is no central optimiser making decisions about the development of the electricity system).

The purpose of with the present paper is to further develop and investigate reasonable investment mechanisms in a simulation model of the electricity system development. In this paper, we extend the model [12] by introducing heterogeneous agents that use individual investment hurdle rates or individual expectations about the future carbon price.

This study also contributes to the literature by looking at one characteristic of the agents at a time and addressing issues such as how the investment in different technologies and the dynamics of the system are affected by heterogeneity. We also analyse the competition among agents with different characteristics, and look at if there are certain characteristics that come to dominate the investments.

Furthermore, this study contributes to the literature by looking at how the investment decisions and the heterogeneity of the agents affect the electricity prices and output variabilities, and how fast carbon emission declines towards carbon neutrality. We also pay attention to how the value of wind is affected by the so-called "cannibalisation effect" in a non-equilibrium model, i.e., that more wind power tends to undercut the value of additional investments in wind. 
In this study, we focus on two characteristics of the agents (hurdle rates and expectations of future carbon price), but we think other heterogeneous characteristics of the agents are also important for their investment decisions, and we wish to analyse those other characteristics in future studies. The reason that we focus on agent heterogeneity in hurdle rates and the future carbon tax is that these two factors are central for power companies when they make investment decisions.

When evaluating the Net Present Value (NPV) of future revenue streams of different generation technologies, investors need to select a discount rate (here referred to as their hurdle rate). This choice has a strong impact on the profitability of different investment options $[12,15,16]$. In general, a high hurdle rate favours options with a low investment cost such as gas-fired power plants, whereas a low hurdle rate tends to favour capital-intensive energy technologies such as nuclear power plants and wind. However, we will in this paper notice that systems effects may complicate this pattern.

When comparing future revenue streams of different technologies, investors also need to estimate the future carbon price since the level of the carbon price will impact the running cost of the fossil technologies, the merit-order and therefore impact the profits of different technologies. A recent survey shows that companies worldwide are using (or planning to use) the internal carbon price for their investment and business operations, and power and fossil fuel industries have the highest proportion of companies currently using (or planning to use) an internal carbon price [17]. (An internal price is a monetary value on greenhouse gas emissions a company considers when making investment decisions and operating businesses). However, there are uncertainties in future carbon price levels (i.e., see the carbon price in the EU Emission Trading System [18,19]), and companies expect different future carbon prices [20]. Studies show that different carbon price assumptions and scenarios can lead to very different investment decisions (see, e.g., [21-23]). Therefore, it is important to consider how the competition between companies with different expectations for the future carbon tax may play out.

In Section 2 we present the model and our scenario assumptions, in Section 3 we describe three separate cases designs (one homogeneous agent case and two heterogeneous agents cases), and in Section 4 we present and discuss our results. In Section 5 we provide our main conclusions.

\section{Methodology}

\subsection{Model Description}

\subsubsection{Overall Structure}

We develop an agent-based model of the electricity system. The agents are individual power companies that (i) operate their power plants in an ideal electricity market and (ii) invest in new power-generating capacity. The agents choose investments to maximise their estimated profits (based on their expectations about the future).

\subsubsection{Technologies}

There are six power generation technologies: coal-fired, natural gas combined cycle (NGCC), NGCC with carbon capture and storage (NGCC with CCS), nuclear, solar PV, and wind power. The plants are characterised by their capacities, fuel costs, investment costs, lifetimes, and $\mathrm{CO}_{2}$ emission intensities. The NGCC plant can be fuelled by natural gas or biogas, a decision made by the plant owner based on which has the lower operating cost when including the carbon tax. (For details on the parameter settings, see Table S1 in Supplementary Materials).

\subsubsection{Time Slices}

When modelling the power system in which variable renewable power sources may provide significant shares of the power supply, the model needs to address the variability of both supply and demand over time. In our model, we divide each year into 64 time slices 
individually characterised by electricity demand and the availability of variable renewable supply from wind and solar (for details, see Supplementary Materials).

\subsubsection{The Electricity Market}

We assume an ideal electricity market and that the agents do not engage in strategic behaviour. Instead, they sell all the electricity they can generate so long as the electricity price is greater than (or equal to) the operating cost of the corresponding plant, following the merit order. This defines the electricity supply function at each time slice, $\tau$, of the year. An iso-elastic demand function determines the price, $p_{\tau}$, that is reached when the electricity produced meets the demand,

$$
q_{\tau}=q_{0, \tau} \times\left(\frac{p_{\tau}}{p_{0}}\right)^{\epsilon}
$$

where $q_{\tau}$ is the electricity produced and consumed in time slice $\tau$. $\varepsilon=-0.05$ is the elasticity, and the reference demand $q_{0, \tau}$ reflects the varying demand over the year (see the Supplementary Materials) and gives the demand for electricity when the price of electricity equals the reference level $p_{0}$. The reference demand $q_{0, \tau}$ is chosen so that the time slices correspond to the varying electricity demand in Germany in 2011, with $p_{0}=3.25$ EUR $\mathrm{ct} / \mathrm{kWh}$, following Jonson et al. [12] (In the sensitivity analysis, we have tested a case where the electricity demand is growing over time. See Section S5.4 in the Supplementary Materials). The carbon tax is part of the operating cost for fossil-fuel-based technologies and thus influences the electricity supply function.

\subsubsection{The Investment Decision Process}

The decision process follows the following steps. First, power plants that reached the end of their lifespan are removed from the current installed capacity mix each year. If multiple plants are retiring in the same year, the model removes one at a time. Following any plant removal, the agents take turns, in a randomly set order, making investment decisions for new plants. An agent adds a hypothetical power plant (testing the range of available technologies) to the existing capacity mix. The agent can calculate the electricity price (see Equation (1)), production profile, and the expected annual profit of this newly added plant for next year.

The agent knows the $\mathrm{CO}_{2}$ tax rate for the next year. Agents thus have a good estimate of revenues and costs for the first year after an investment, even though subsequent investment decisions may alter the capacity mix and thereby change the estimated profitability. However, the agents have limited information about the $\mathrm{CO}_{2}$ tax and the electricity prices for subsequent periods. In the simplest setting, agents assume that both the $\mathrm{CO}_{2}$ tax and the estimated annual profit remain constant throughout the life of the power plant. (We also expand the model to allow for more advanced agents that have different expectations on the $\mathrm{CO}_{2}$ tax ten years into the future, see Section 3.) The agent chooses the investment option with the highest positive profitability index, i.e., the highest profit per invested EUR corrected for the lifetime of the plant.

$$
\begin{gathered}
\text { profitability index }=\frac{N P V}{I} \times C R F \\
C R F=\frac{r}{1-(1+r)^{-T}}
\end{gathered}
$$

where NPV is the Net Present Value of all future revenues and costs, $T$ is a plant's lifespan, $I$ is a plant's investment cost, and $r$ is the hurdle rate used by the agent. By multiplying the $N P V$ with the capital recovery factor $(C R F)$, investment projects with different lifespans can be compared [24,25]. (We correct for the life of the investment in order to enable a fair comparison across technologies. However, it turns out that differences in plant lifespans in the relevant range (say, 20 to 40 years) do not make a major difference to the results since revenues 20 to 40 years into the future are discounted rather heavily.) 
Following an agent's decision, all agents are informed and take the information into account in subsequent decisions. These decision rounds continue as long as agents are willing to invest. Then, the next plant is removed, and a new round of decisions takes place, until all plants to be retired in that year have been removed from the capacity mix. The newly invested plants are added to the capacity mix and start producing electricity the following year.

As the process of "out with the old, in with the new" repeats every year, the capacity mix keeps changing over time. In the present version of the model, agents do not take their current plant portfolio into account when evaluating an investment. (One could argue that a company with lots of, say, coal-fired power plants should not invest in wind if that investment would reduce electricity prices and induce lower profits or even losses for the coal-fired power plants. However, if the wind plant is profitable, it is likely that another company would carry out the investment anyway, and therefore electricity prices would drop by as much, but the profits from the plant would just accrue to some other company. That said, incumbent energy companies may still be less willing to invest in new technologies. In future work, we plan to consider how strategies that optimise the profitability of a company's entire portfolio may affect the overall development of the power system and the performance of each company).

\subsection{Carbon $\operatorname{Tax}$}

In the scenario investigated, we assume a rising carbon tax that is zero during the first 10 years, after which it grows linearly to $100 \mathrm{EUR} /$ ton $\mathrm{CO}_{2}$ in year 50 and then stays there.

\section{Case Design: Homogeneous and Heterogeneous Agents}

We investigate three cases for the model set-up, a base case with homogeneous agents and two cases with heterogeneous agents: in one, the agents apply different hurdle rates; in the other, they instead make different assumptions about the rate of the future $\mathrm{CO}_{2} \operatorname{tax}$.

\subsection{Homogeneous Case}

In the homogeneous case, all agents are identical. They use the same hurdle rate ( $8 \%$ /year), employ the same investment decision criterion, and have the same expectations about the future. They know the carbon price for the next year. They also know the present and already planned power generation capacity. They assume that the carbon price, power capacity, and electricity prices that are estimated for the subsequent year remain constant thereafter.

\subsection{Heterogeneous Hurdle Rates (HHR) Case}

In the second case, 25 agents use hurdle rate values between 5\% and 11\% per year (with steps of $0.25 \%$ ). We want to investigate how the market develops if companies exhibit different degrees of risk aversiveness (and we assume that this is expressed by using different hurdle rates). We will refer to this case as the heterogeneous hurdle rate (HHR) case. In this run, all agents have otherwise the same expectations for the future as in the homogeneous case.

Here, we assume a hurdle rate of $8 \%$ /year in the base case, but in the heterogeneous cases, we have a range from $5-11 \% / y r$. The base case value and the range are based on studies by IEA [26] who reported a weighted average cost of capital (WACC) for major power companies of around 8\%/year in 2006 and a drop to around 5\%/year in 2018. IRENA [27] reports a real WACC equal to 7.5\%/year for OECD countries and China, and $10 \%$ /year for the rest of the world. The National Energy Modelling System (NEMS) of the US Energy Information Administration estimates a WACC of roughly 7\%/year (see Figure 8 in Appendix 3. C in [28]), and a recent EU study reported that WACC varied across the EU Member States from 3.5\%/year in Germany to 12\%/year in Greece for onshore wind projects in 2014 [29]. 


\subsection{Heterogeneous Foresight (HF) Case}

In the third case, there are 16 agents with different expectations about the future growth rate of the carbon tax. We will refer to this case as the heterogeneous foresight (HF) case. In this case, an agent uses the future $\mathrm{CO}_{2}$ tax rate (as per its expectation), along with the current capacity mix (including already-made decisions), to estimate the cash flow 10 years ahead. The agents expect future $\mathrm{CO}_{2}$ tax levels $E_{t+10}(\beta)$ that increase linearly from the known level $T_{t+1}$ in the next year $(t+1)$ to a future level 10 years ahead $(t+10)$, as described by the following expression,

$$
E_{t+10}(\beta)=T_{t+1}+\beta\left(T_{t+10}-T_{t+1}\right)
$$

where $t$ is the current year, and $\beta$ reflects the expected growth rate of the $\mathrm{CO}_{2}$ tax, ranging uniformly from 0 to 1.5 (with steps of 0.1 ). This means that agent 1 (with $\beta=0$ ) believes that the $\mathrm{CO}_{2}$ tax will not increase, and agents 2 to 10 underestimate the growth of the tax, while agent 11 (with $\beta=1$ ) expects the true future tax, $T_{t+10}$, and agents 12 to 16 overestimate the tax. Note that the agents calculate the future electricity prices based on their expected $\mathrm{CO}_{2}$ tax. However, all agents assume that the installed capacity mix is unchanged over the next 10 years, apart from the new investment decisions that have already been taken. Linear interpolation is used to estimate the profitability of the different options over time. In the HF case, all agents use an $8 \%$ /year hurdle rate.

In all cases, the model starts from the stationary state at year 0 and runs for 80 years, when the system is close to a stationary state again. Initially, there are only coal and gas power plants, with a total capacity of $64 \mathrm{GW}$ and $2 \mathrm{GW}$, respectively. The initial plants are owned and operated by a separate company that does not take part in further investments. These coal and gas plants have varying remaining lifetimes and are gradually removed from the system over time. (We also test a case where there are external PV investments from the households. See Section S5.3 in the Supplementary Materials).

\section{Results and Discussion}

We present our results from both the system-level perspective and the agent perspective. For the system level, we present the installed capacity, electricity price and production, price variations, $\mathrm{CO}_{2}$ emission trajectories, and the ex-post evaluated internal rate of return (IRR) for each investment. For the agent level, we present the individual agents' capacity investments and economic performances. We also compare our model results with results from the literature or real-world examples in order to corroborate the model.

\subsection{Installed Capacity}

In all three cases, coal-fired power plants are gradually phased out from the capacity mix as a result of the increasing carbon tax. Meanwhile, the installed capacities of all other technologies increase, but to varying degrees.

This pattern can also be observed in the real world, for example, the increasing carbon price in the EU ETS has led to a rather rapid reduction in coal used for electricity generation (in particular over the last years), and an increasing use in variable renewable energy $[30,31]$. The growth in solar and wind has historically primarily been driven by various support schemes, but with current EU ETS prices, investments in these technologies become profitable even without other support schemes.

\subsubsection{Homogeneous Case}

In the homogeneous case (Figure 1a), the installed capacity of coal starts to decline around year 15. At that time, investments in wind starts to grow, but the installed capacity of wind begin to decline some twenty years later due to competition from nuclear, which then expands significantly (Figures 1a and 2a). It is interesting to note that this happens for purely economic reasons despite the fact that the assumed levelised cost of wind is significantly lower than that of nuclear in the model. 


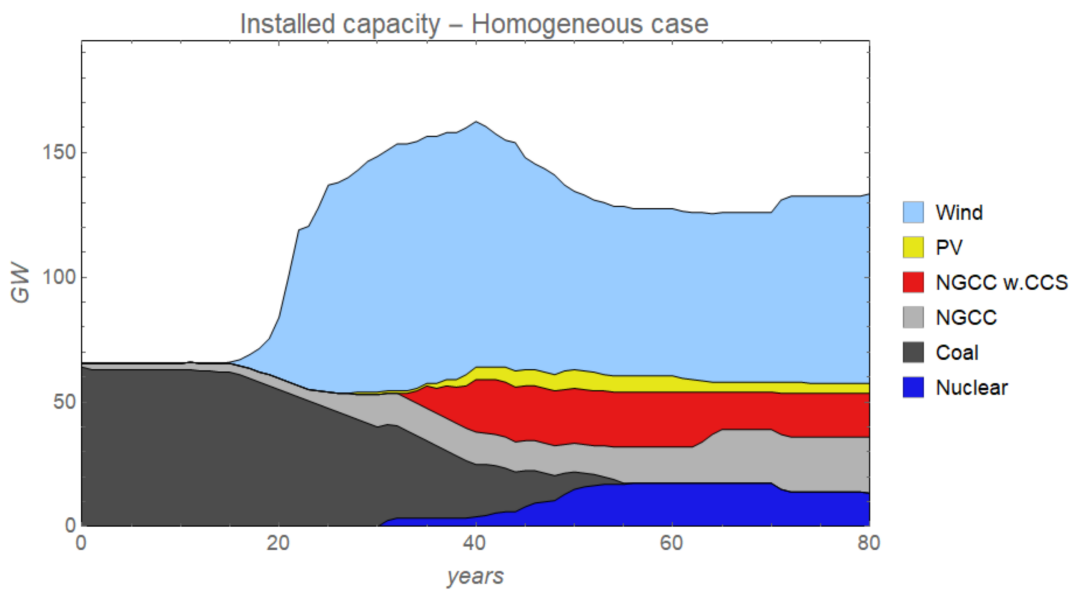

(a)

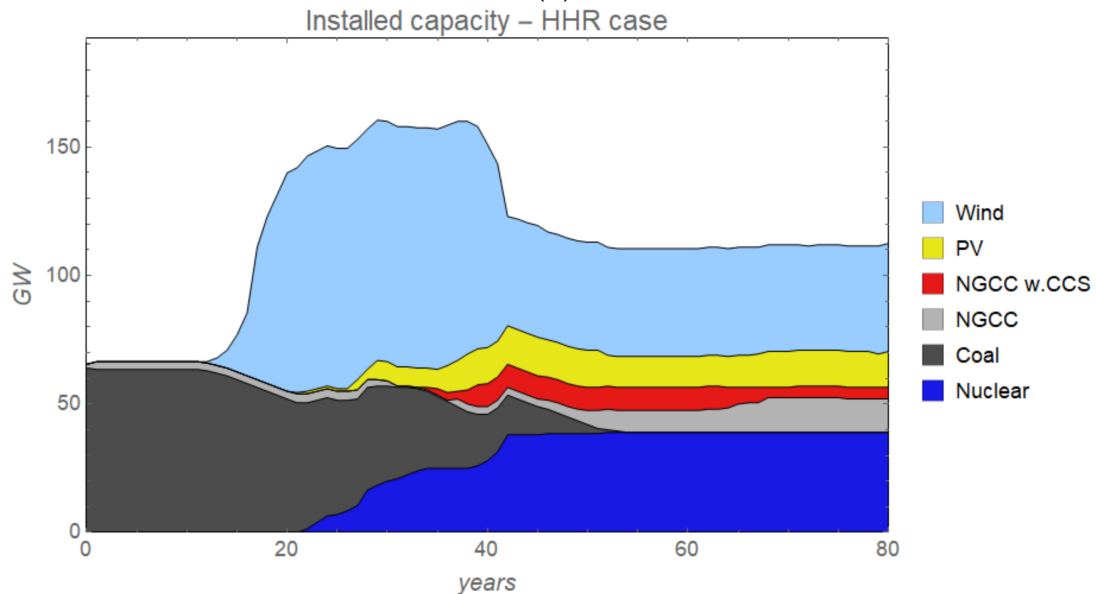

(b)

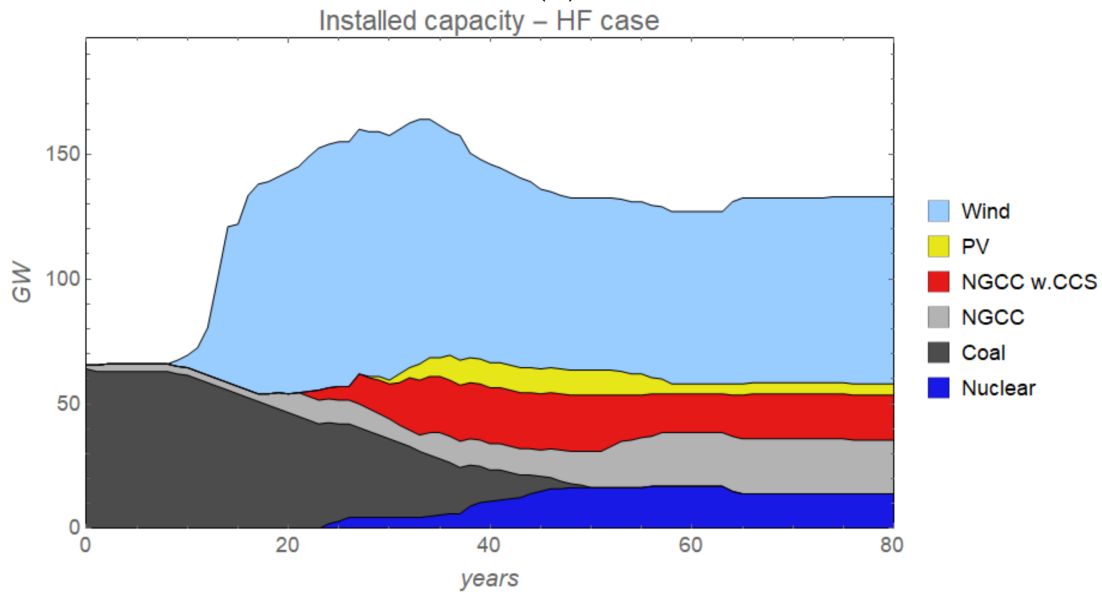

(c)

Figure 1. Installed capacity in the (a) homogeneous case, (b) HHR case, and (c) HF case. In all three cases, the capacity mix goes from coal-based to low-carbon, but the transition speed and final mix vary. 


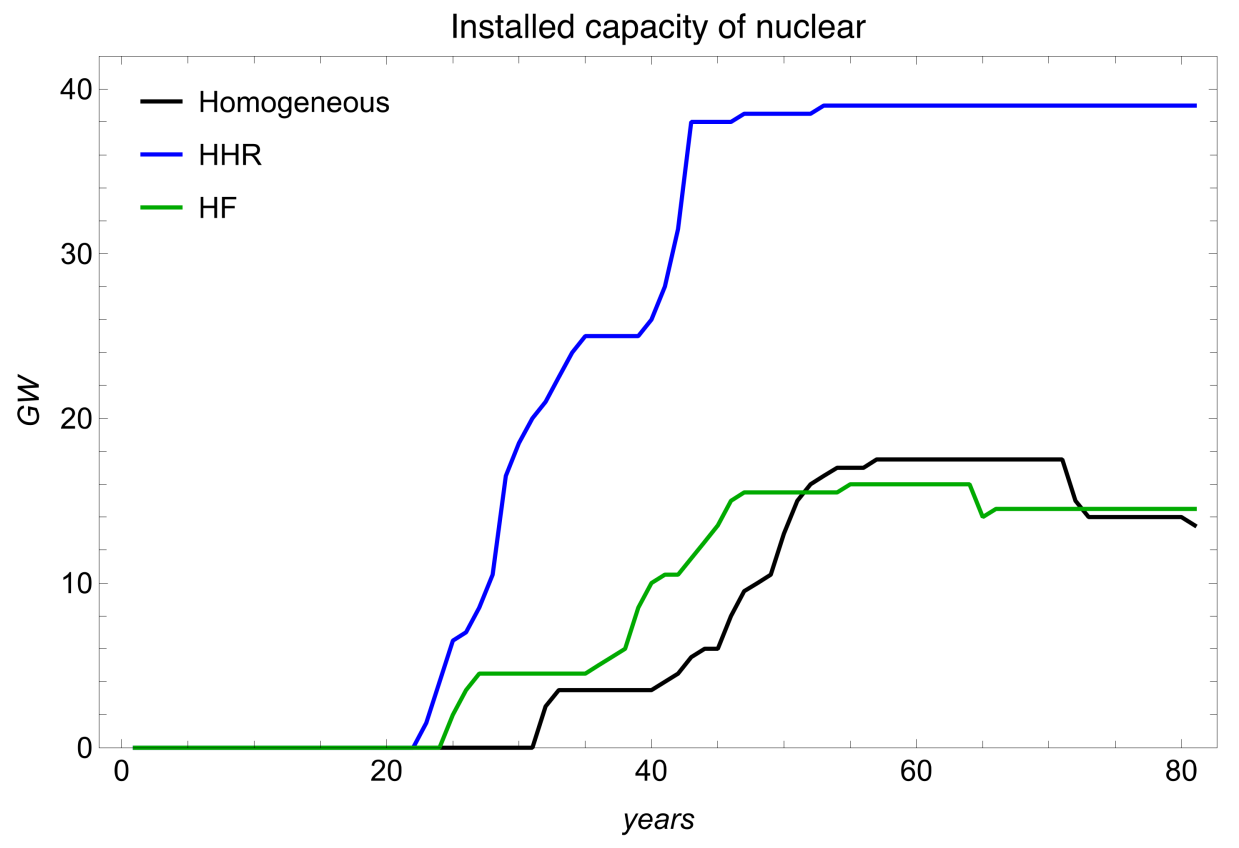

(a)

Installed capacity of wind

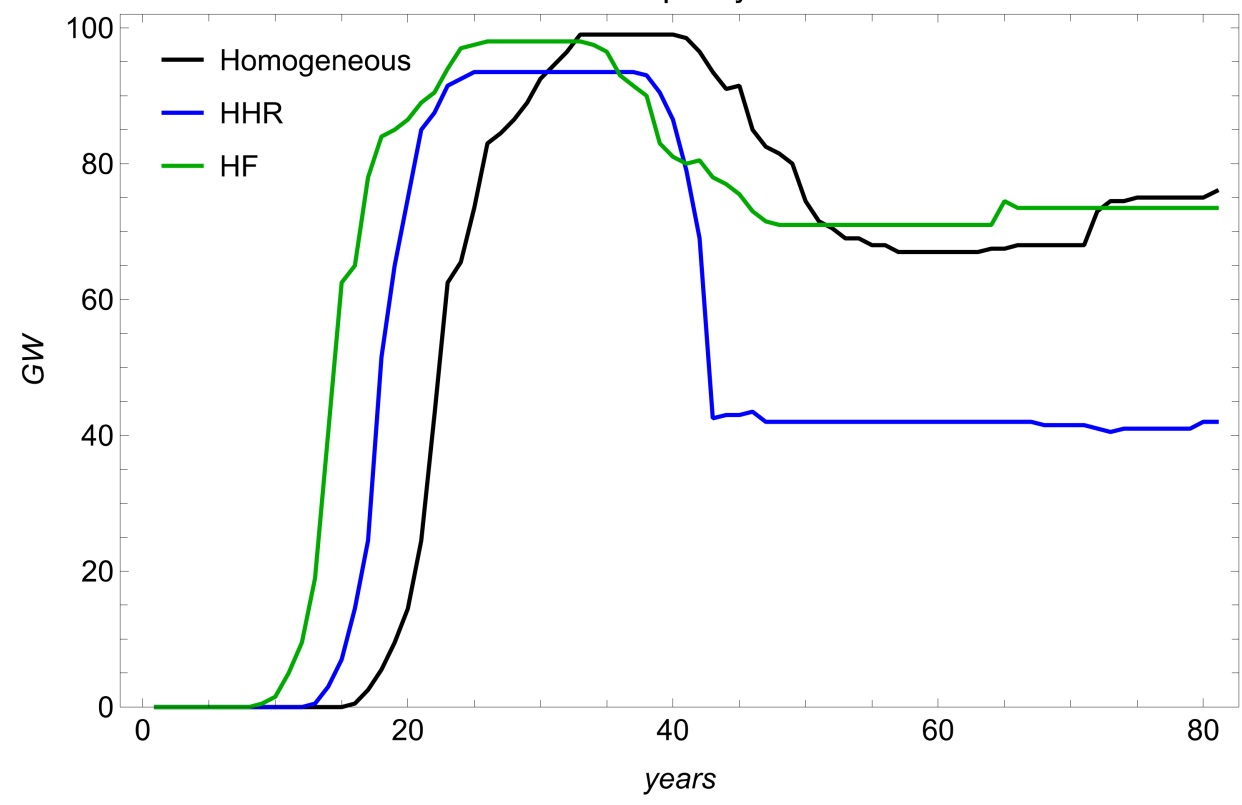

(b)

Figure 2. Installed capacity by technology in homogeneous, HHR, and HF cases. (a) Nuclear, (b) wind. In the HHR case, there is significantly more nuclear and less wind. The earliest wind expansion is observed in the HF case.

This illustrates why the levelised cost of electricity (LCOE) metric is inappropriate when comparing the competitiveness of, in particular, dispatchable technologies such as nuclear and gas-fired power plants with that of intermittent technologies such as wind and solar [32]. The fundamental reason for this is that the LCOE metric does not consider that the price of electricity varies during the course of a year and hence that different generation technologies will receive different average revenues per $\mathrm{kWh}$ of electricity produced. Therefore, in this case, when the installed capacity of wind grows to sufficiently high levels, wind eventually begins to receive lower revenues per $\mathrm{kWh}$ than does nuclear 
(because they produce power at different points in time). (See more about the revenue and value factor of wind in Section 4.2.2.)

\subsubsection{Heterogeneous Hurdle Rate (HHR) Case}

In the HHR case, nuclear starts to grow earlier and at a higher rate compared to the homogeneous case (see Figure 2a). By the end of the period we have $40 \mathrm{GW}$ nuclear in the HHR case compared to some $15 \mathrm{GW}$ in the homogeneous case. We also see an earlier introduction of wind in the HHR case than in the homogeneous case. Interestingly, towards the end of the period, the installed wind capacity is significantly lower in the HHR case ( $75 \mathrm{GW}$ in the homogeneous case, but $42 \mathrm{GW}$ in the HHR case, see Figure $2 \mathrm{~b}$ ). The impact of agent hurdle rate heterogeneity in the long run is thus different for wind and nuclear.

The explanation for this has two steps. First, when the model is run with heterogeneous hurdle rates, the investments are unevenly distributed among the agents (Figure 3), and the agent with the lowest hurdle rate (5\%/year) does almost all the investing. With a low hurdle rate among those who carry out almost all the investments, the levelised costs of both nuclear and wind drop more than the cost of coal does, so wind and nuclear are introduced earlier than in the homogeneous case.

Installed capacity for four agents (HHR case)

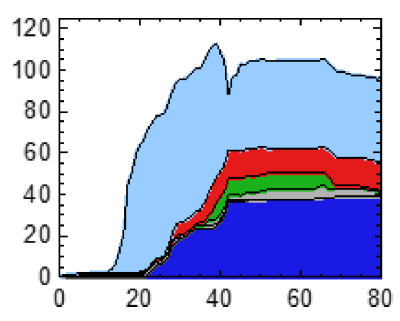

(a)

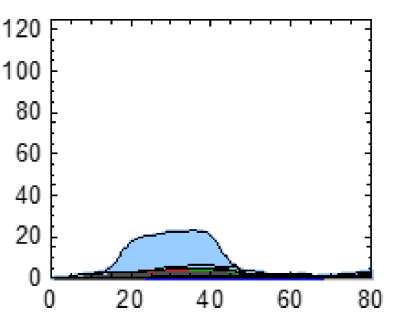

(b)

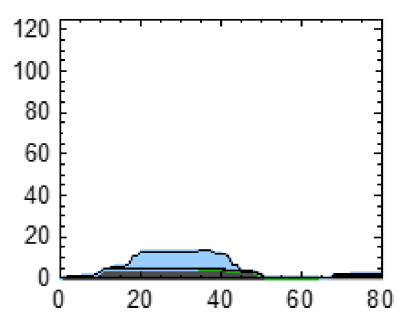

(c)

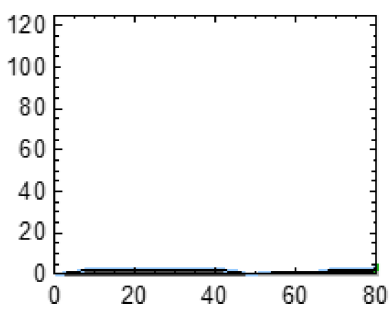

(d)

Figure 3. Illustration of the installed capacity for some agents in HHR case, (a) $r=5.0 \%,(\mathbf{b}) r=5.25 \%$, (c) $r=5.5 \%$, (d) $r=5.75 \%$. The agent with $r=5 \%$ dominates the investing, while agents with $r>6.75 \%$ make no investments.

Second, the lower hurdle rate makes the cost of nuclear drop more than for its dispatchable competitors-NGCC — and natural gas with CCS, and therefore nuclear takes market shares from these technologies. Now, since wind and gas-fired power plants tend to be more complementary to, than competitive with, each other [12,33], the installed wind capacity actually drops as a consequence of the decline of gas-fired power plants (both NGCC and natural gas with CCS). Therefore, towards the end of the period, there is significantly more nuclear and less wind in the HHR case than in the homogeneous case. (We conducted a sensitivity analysis of the impact of the hurdle rate on the installed capacity of wind and how it is related to the availability of gas-fired power plants. See Supplementary Materials for details).

When looking at the HHR case from the agent's investment perspective, we see that while the agent with the lowest hurdle rates (5\%/year) dominates investing, agents with hurdle rates over $6.75 \%$ /year do not make any investments at all (see Figure 3a-d). This is because agents with lower hurdle rates are more willing to invest than other agents, as they have a lower requirement on future net revenues, which in turn lowers the electricity price. This reduces returns on investment so much that agents requiring a higher return never invest and are largely outcompeted.

Our finding here also supports the results in $[13,14]$, where they find that with agents applying various hurdle rates, the transition to a low-carbon system is accelerated due to 
the investments from agents that apply lower hurdle rates, and those agents take a major share of the investments [34].

\subsubsection{Heterogeneous Foresight (HF) Case}

The expansion of wind and nuclear in the HF case is similar to the expansion in the homogeneous case, and the installed capacity in these two technologies towards the end is roughly the same as in the homogeneous case, but investments in wind and nuclear start a decade earlier than in the homogeneous case.

However, one interesting difference is the faster phase-out of coal plants (compared to in the other two cases) and the expansion of gas-fired power plants is much faster, and this in turn depends on two factors: (i) the agents have 10-year foresight, so many of them expect that the carbon tax will be higher in the future, and that prompts them to invest in gas with CCS earlier; and (ii) some agents expect a carbon price that is even higher than the one that eventually materialises, and this creates an even stronger incentive to act early. These findings can be also observed in the actions taken by companies in the energy sector. For example, the Dutch company Shell expects the carbon cost to increase to more than $\$ 100$ per tonne of GHG emissions by 2050, and this high price expectation influences Shell's decisions to invest in carbon capture technology (as well as investments in natural gas and biofuels) [35].

Agents that anticipate a high carbon price dominate the overall investment activity (but only prior to the stabilisation of the carbon price). Figure 4 shows that the agent that expects the highest carbon price makes most of the investments during the transient phase (years 10 to 50). This agent (falsely) believes the electricity price will be higher than the other agents think, due to overestimating the future carbon price. However, during the final 20 years, when the carbon price has stabilised, all agents foresee the same future carbon price, and they all invest and gradually approach equal installed capacities.

Installed capacity for four agents (HF case)

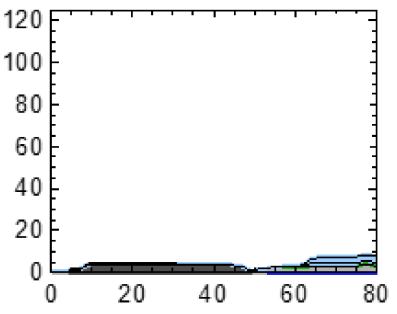

(a)

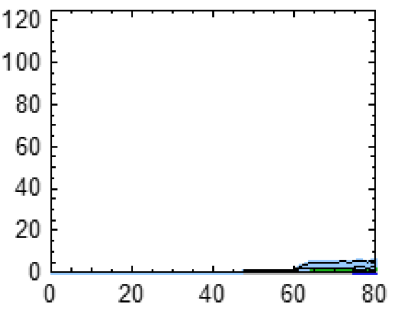

(b)

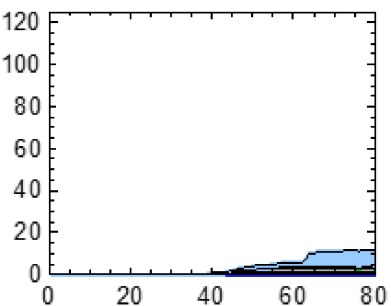

(c)

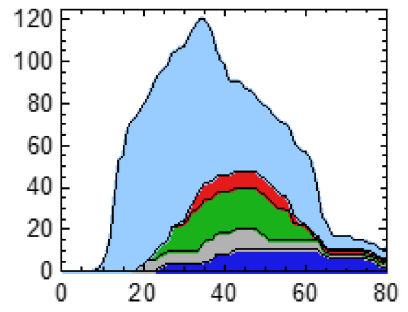

(d)

Figure 4. Illustration of the installed capacity for some agents in HF case. (a) $\beta=0.0,(\mathbf{b}) \beta=1.0$, (c) $\beta=1.2$, (d) $\beta=1.5$. ( $\beta$ is the multiplication factor of expectation of $\mathrm{CO}_{2}$ tax). The agent with $\beta=1.5$ dominates the investing in the first 50 years; afterwards, all agents contribute to investing in new capacities.

\subsection{Electricity Price and Production}

\subsubsection{Average Electricity Price}

The annual average electricity price increases over time in all three cases, but to different degrees and at different speeds (Figure 5). The electricity price increases because the growing carbon price results in higher marginal costs of the fossil plants, which sets the market price. Once essentially all $\mathrm{CO}_{2}$ emissions are phased out, the electricity price is nevertheless higher than in the beginning of the modelling period, since the cost of the technologies that replaced coal are higher than the cost of coal. 


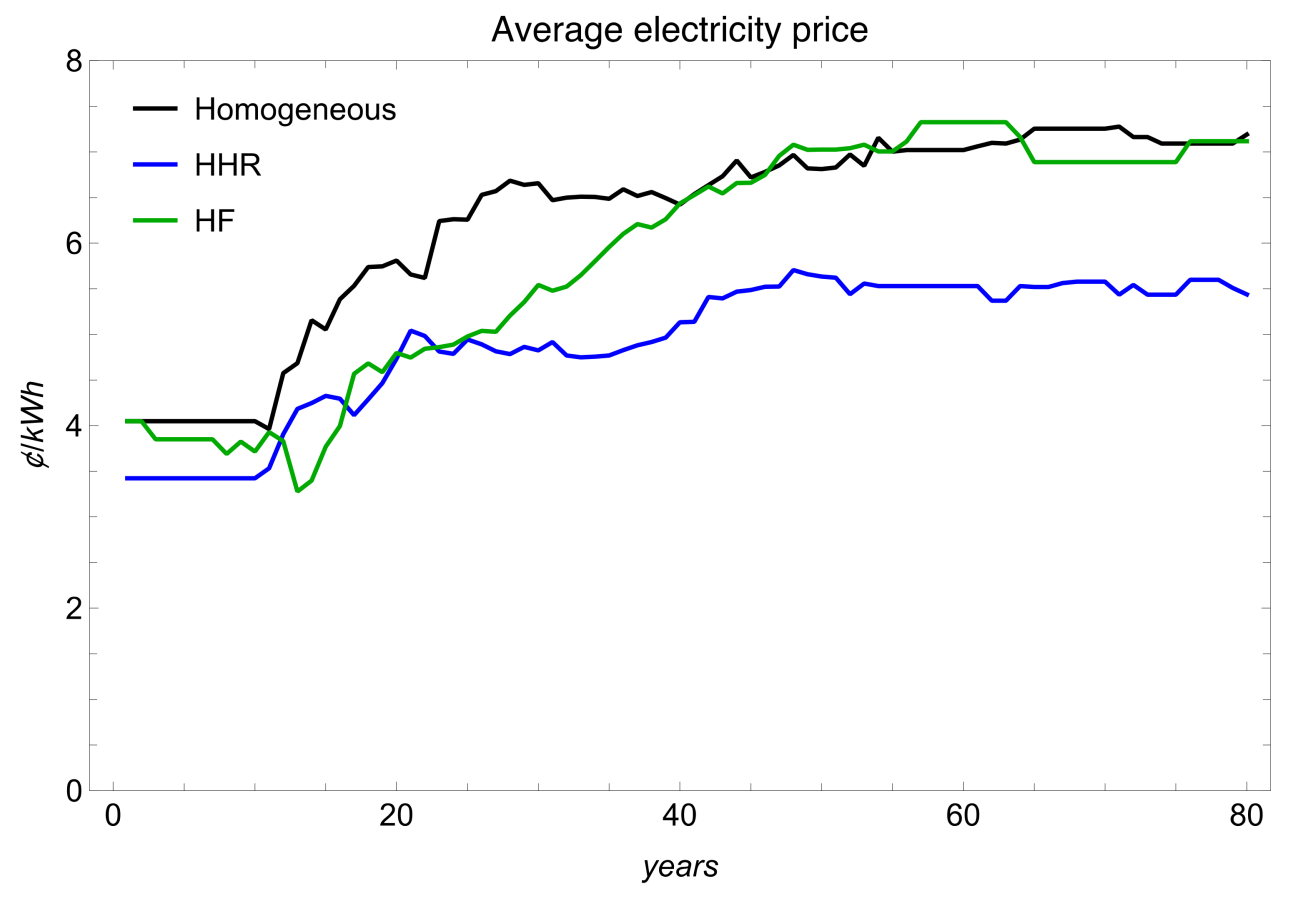

Figure 5. Average electricity prices for the homogeneous case, HHR case, and HF case.

In the long run, the electricity price is the same in the HF case as in the homogeneous case, because the $\mathrm{CO}_{2}$ tax stabilises (and the hurdle rate is the same). However, in the near term, the electricity price is lower in the HF case, since agents invest more heavily in the wind as some agents believe that carbon prices will be higher than they really turn out to be. This increases available capacity and hence lowers electricity prices during the transient phase.

In the HHR case, due to the lower hurdle rate applied by the dominating agent, the price increase is smaller. In this case, the agents use lower hurdle rates, so with a lower cost of capital it becomes less costly to produce electricity, and therefore the price of electricity drops in a competitive market.

\subsubsection{Average Revenues per kWh Received by Wind-The So-Called "Cannibalisation Effect"}

Several studies have found that as the installed capacity of wind increases, the value of wind (the average electricity price received by wind producers) tends to drop [36-38]. The average revenues per $\mathrm{kWh}$ received by wind producers are expected to drop in absolute terms if the wind is introduced through, for instance, an investment subsidy (this is what is sometimes referred to as the cannibalisation effect). However, here we find that when wind is introduced as a result of an increasing carbon tax, the revenue received by wind generators will not drop in absolute terms but in relative terms (see Figure 6a,b). Our results here corroborate the findings by Brown and Reichenberg [39] and Jonson et al. [12]. The reason why the absolute value of wind does not drop is that on a competitive market, agents will not invest in wind if the average revenues received per $\mathrm{kWh}$ are lower than the levelised cost of wind. The reason why the relative value (the wind value factor) tends to drop is that while the average revenues per KWh received by wind operators remain roughly constant, the average electricity price increases in response to the increasing carbon tax. Hence, the relative value of wind drops. 


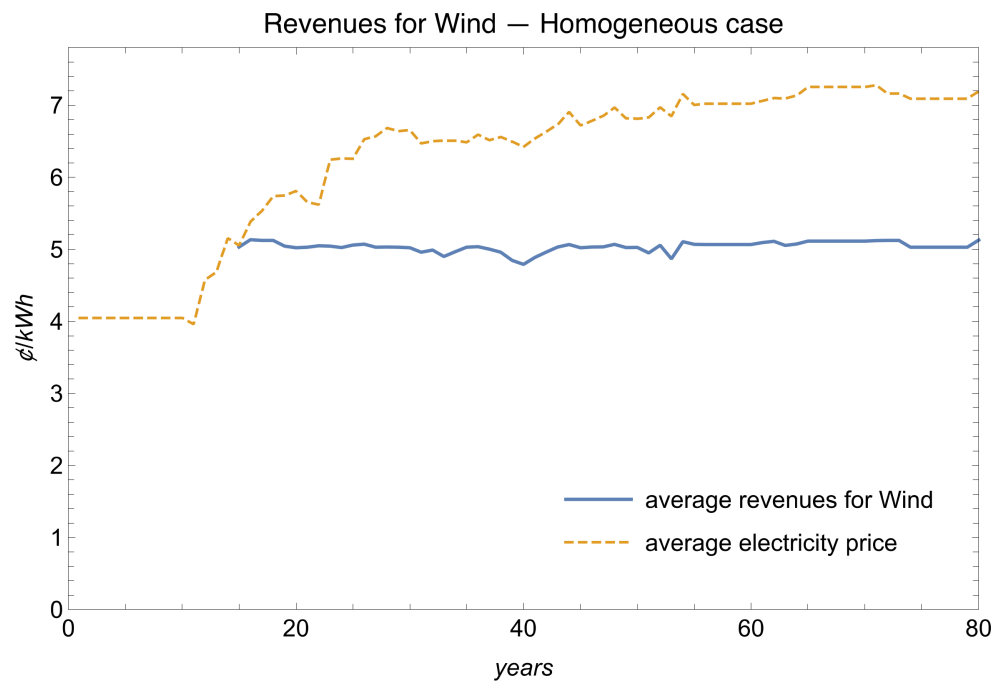

(a)

Ratio: Average revenues for Wind / average electricity price

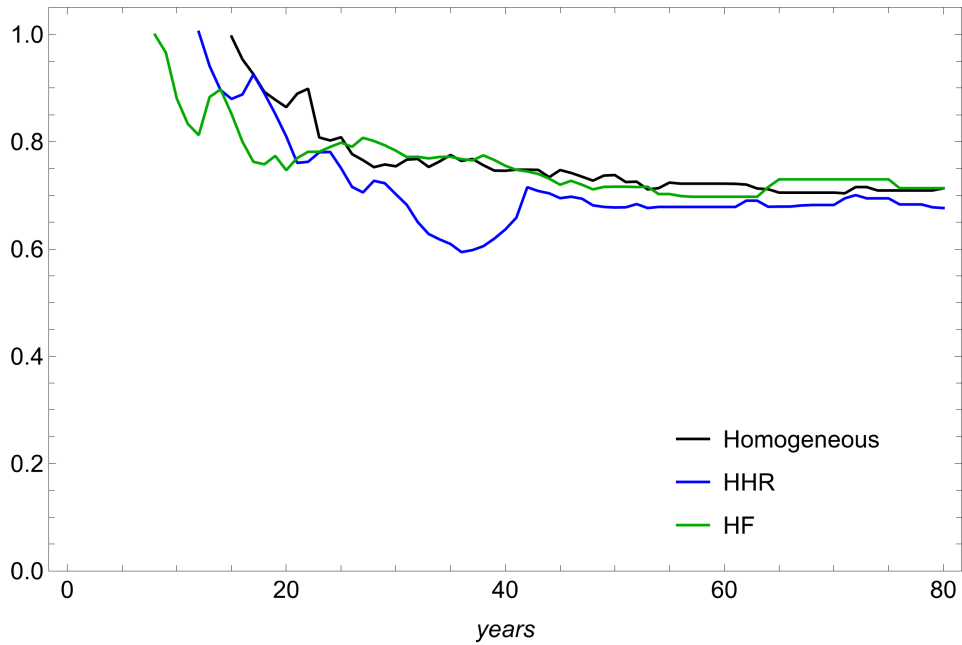

(b)

Figure 6. Revenues received by wind: (a) in absolute term (homogeneous case), (b) in relative term (all three cases).

\subsubsection{Electricity Price Variations}

Another important question for a transition towards a greater share of variable renewable energy is whether and to what extent price variations are more pronounced over the course of the year. Studies, e.g., [40-42], have shown that the higher share of renewable energy has increased the variance of wholesale electricity prices. Our results here show a similar pattern.

Figure 7 shows the amount of electricity produced at different prices for the homogeneous case. In year 5, while coal still dominates production, we see that most electricity is produced and sold at 3-4 EUR ct/ $\mathrm{kWh}$, but there is also some electricity produced at around 20 EUR ct/kWh, associated with $\sim 500 \mathrm{~h}$ of the highest reference demand. In year 25, most electricity produced, from both wind and coal, is sold at 5-6 EUR ct $/ \mathrm{kWh}$. Meanwhile, the high wind capacity can result in very low prices, $\sim 1 \mathrm{EUR} c t / \mathrm{kWh}$, as well as very high prices, 25 EUR ct/kWh or above, for some hours of the year (a similar observation has been made by Auer and Hass [43]). When agents have invested heavily in wind, there is less incentive to invest in other technologies (because prices have been depressed), and when demand is high and wind output is low during certain hours of the year, prices may become very high. By year 40, the expansion of wind has led to a situation with many hours having 
a price level of less than 1 EUR ct/kWh. However, the high price spikes are damped by the increased presence of biogas, natural gas with CCS, and nuclear power (see Figure 7 for year 80 ). The price variation is also presented by the 10th and 90th percentiles in the Supplementary Materials, see Figure S6a-c.
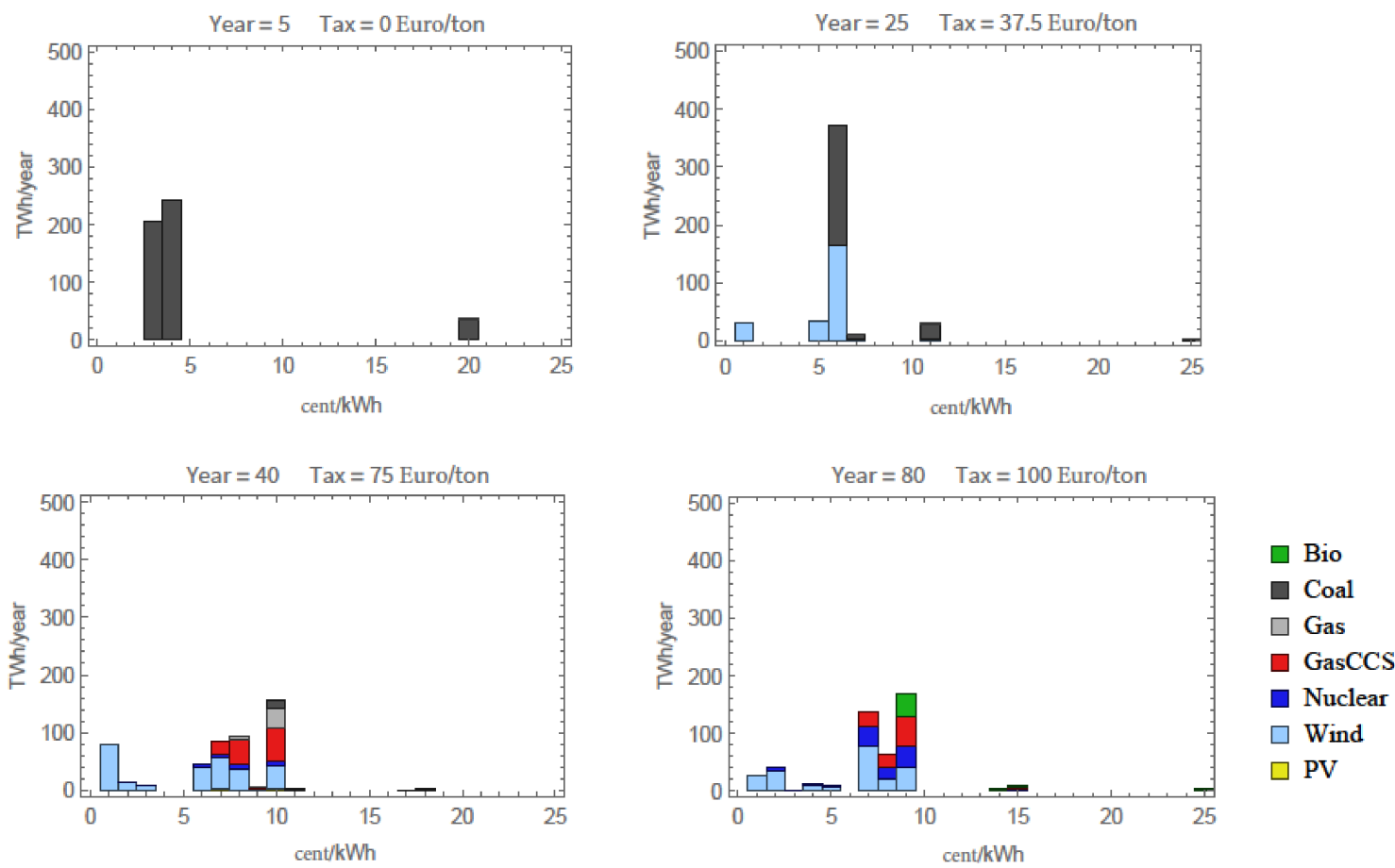

Figure 7. Power output at different price levels for four years (years 5, 25, 40, and 80) in the homogeneous case. Each column represents all production sold at prices in an interval $[p-1, p]$ EUR cent $/ \mathrm{kWh}$, for integer values of $p$. The 25 EUR cent level also collects all production from higher prices. Each column shows produced amounts in merit order from bottom to top.

\section{3. $\mathrm{CO}_{2}$ Emissions}

As the electricity system shifts from a coal-based mix to low-carbon energy sources, $\mathrm{CO}_{2}$ emissions drop from around 480 megatons per year to 5 megatons in the homogeneous and HF cases, and to 1 megaton in the HHR case (Figure 8). The earliest emission decline happens in the HF case.

The HF case illustrates that the uncertainty about future carbon prices may lead to a faster transition. However, this result does not hold if "uncertainty" is interpreted as if companies are uncertain whether the tax will increase at all and the true subsequent increase is higher than what all the companies expected (see e.g., Figure S9 in Supplementary Materials, where we compare the rate of emission reductions in a case where agents have a one-year correct foresight for the carbon tax and a ten-year correct foresight).

What we have found (and estimated the impact of) is a case where the companies are uncertain about how much the carbon tax will increase and some companies expect that carbon tax will increase more than it eventually does, while others expect it will increase less. 


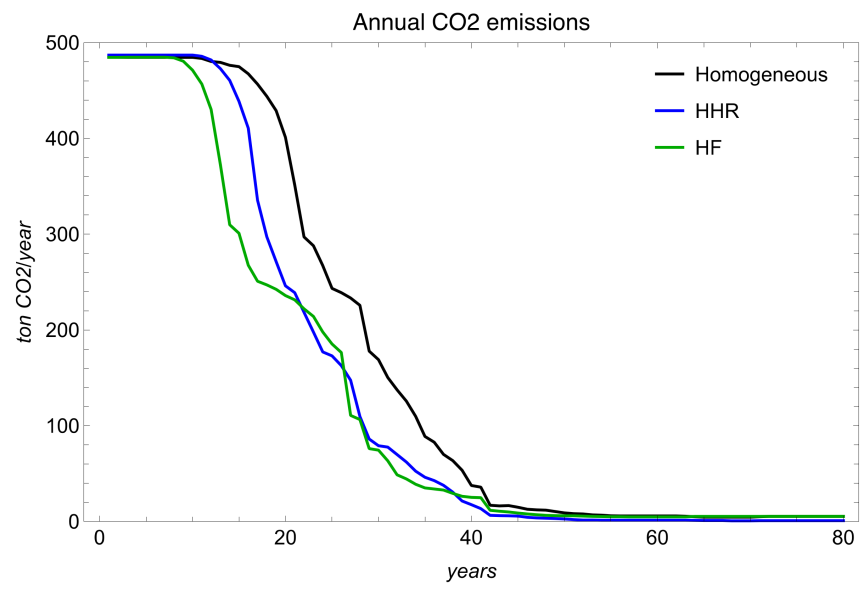

Figure 8. Annual $\mathrm{CO}_{2}$ emissions trajectory for the homogeneous case, $\mathrm{HHR}$ case, and $\mathrm{HF}$ case.

4.4. Economic Performances-Ex-Post Analysis of the Investments 4.4.1. Internal Rate of Return of Investments

Figure $9 \mathrm{a}-\mathrm{c}$ show ex-post analyses of the profitability of the investment projects over time. We compare the internal rate of return (IRR) for all investments done in the three cases. Each dot represents an investment that was made in a particular year.

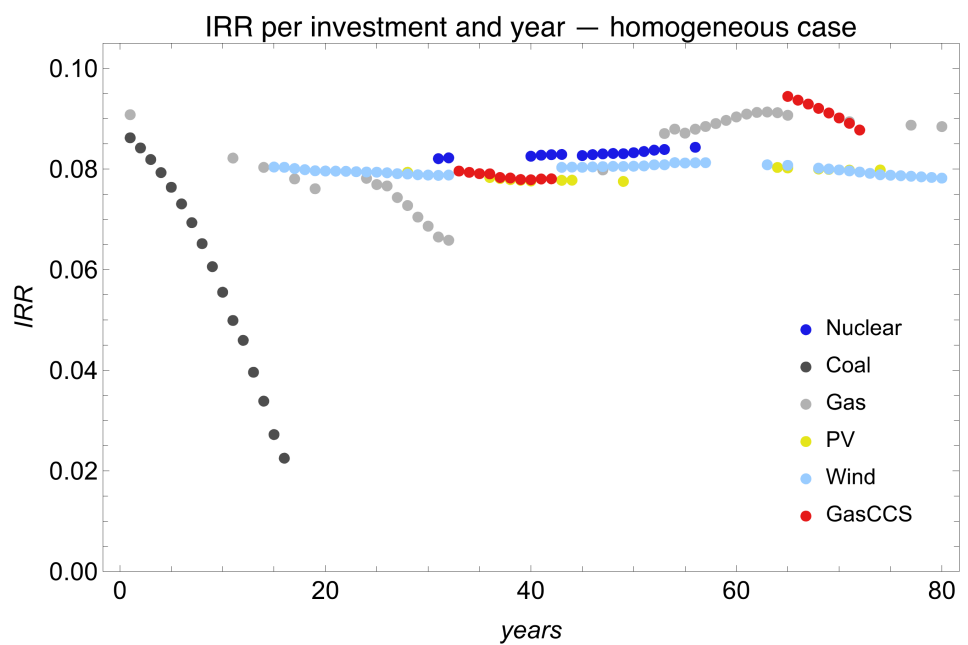

(a)

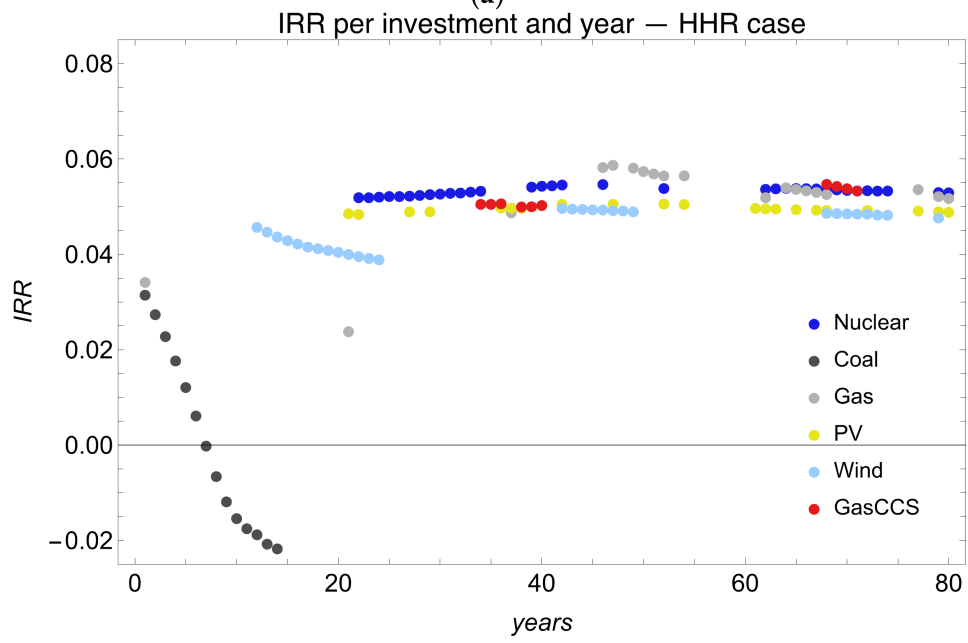

(b)

Figure 9. Cont. 


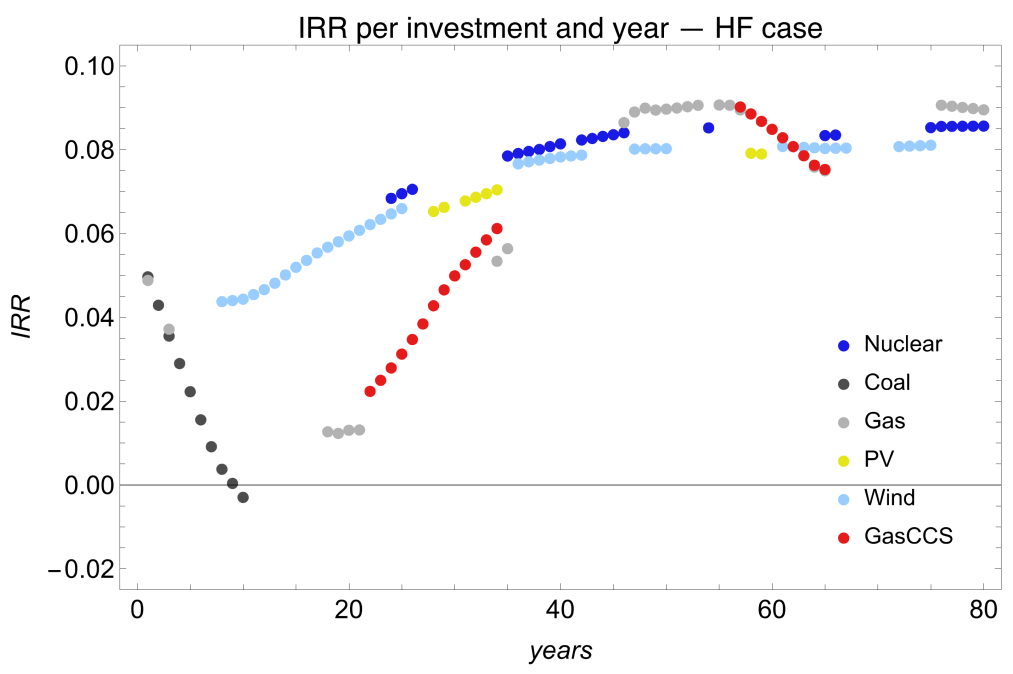

(c)

Figure 9. Internal rate of return (IRR) of investments in the (a) homogeneous case, (b) HHR case, and (c) HF case. Except for coal, the IRRs are mainly close to the level of the hurdle rates used by agents who make the investments.

In the homogeneous case, the IRR of coal drops rapidly from above $8 \%$ to $2 \%$ per year. This is because the increasing carbon tax makes investments in coal-fired power plants increasingly unprofitable. The reason why investments are nevertheless made in this technology is that the agents do not foresee the increase in the tax. For gas plants, the IRR declines during the first 30 years due to the carbon tax, but after switching to biogas around year 42 , the IRR goes up and exceeds $9 \%$ per year at its highest. Meanwhile, all other investments have an IRR around $8 \%$ per year, which indicates that agents in general are close to the target set by their hurdle rate, despite their limited foresights (the reason we do not get exactly $8 \% /$ year is that (i) we have limited foresight so all investments are not perfect, and (ii) we have discrete name plate capacities, which means we cannot invest to get the exactly "optimal" solution).

The declining profitability of coal power can be observed in Germany and the EU. Analyses have shown that the coal plants have been operating at a loss in recent years due to the carbon price in the EU ETS and competition from renewable energies [44,45].

In the HHR case, IRRs of most investments are around 5\%/year, which is the hurdle rate applied by the agent that made almost all the investments. The IRR of coal is even lower in this case, due to a lower electricity price.

In the HF case, during the first half of the simulation, the IRRs are much lower than in the homogeneous case. This is due to overinvestment by the agent that expects the highest carbon tax, which in turn yields low electricity prices during the transient phase (Figure 5). In the second half period, when the carbon tax begins to stabilise, all agents have roughly correct foresight, and the IRRs of wind and gas grow back to around $8 \% /$ year, similarly to the homogeneous case.

\subsubsection{Economic Performance of Individual Agents}

To measure an individual agent's economic performance, we use a performance index which is defined as the agent's annual profit divided by the total investment costs of all plants it owns. Here we assume that an agent buys a plant by borrowing money from the bank at a $4 \%$ interest rate. The annual profit is then calculated as the revenue minus the operating costs and the annuitised capital costs, where the capital cost is calculated with the $4 \%$ bank rate. This means that the varying hurdle rates assumed by the agents in our model $(5 \%$ to $11 \%$ ) reflect different risk premiums or margins compared to the bank rate. A positive performance index in a certain year thus means that an agent's net revenues cover more than the annuitised capital cost of its plants. 
In the homogeneous case (Figure 10a), the index starts at around 5\%, but falls to $1 \%$ around year 20, due to the dropping revenue from coal investments and large expenditures on wind investments. However, the index gradually grows back to around 3.5\%.

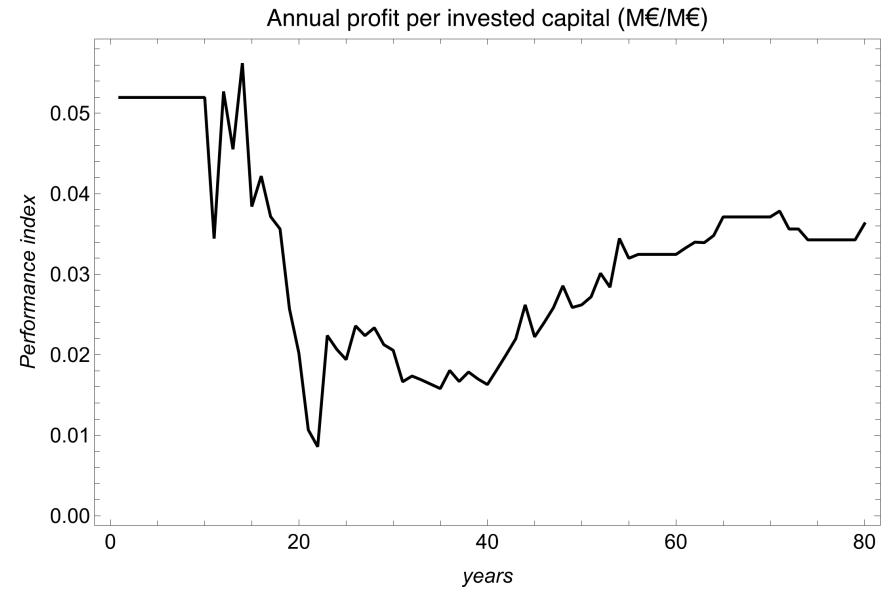

(a)

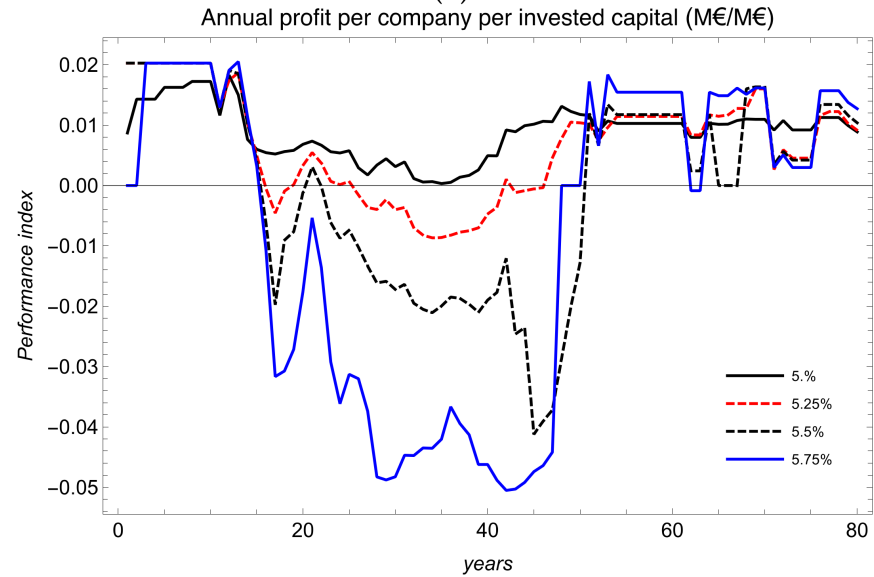

(b)

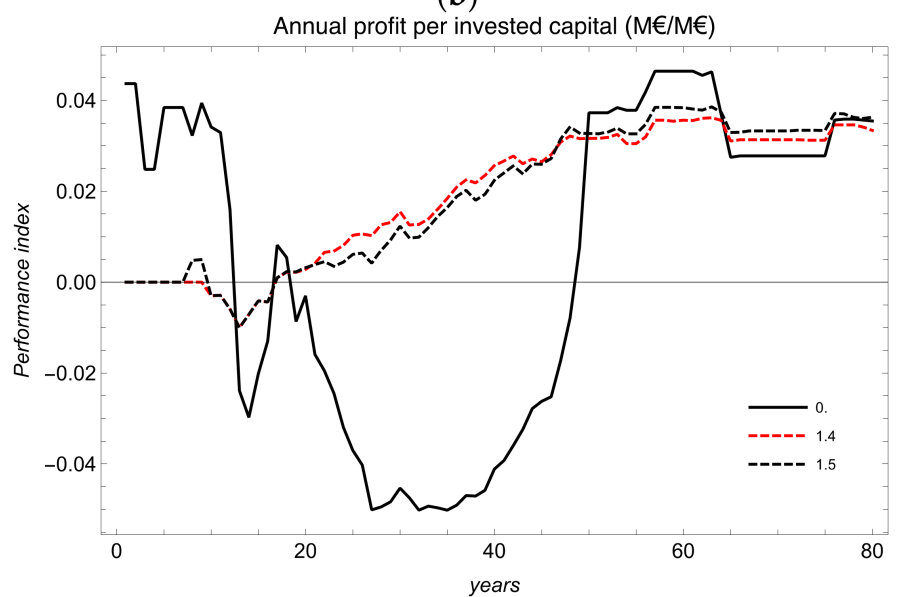

(c)

Figure 10. Individual agents' economic performance in the (a) homogeneous case, (b) HHR case, and (c) HF case. In the homogeneous case, the index stays positive during the whole model run, while in the two heterogeneous cases, the index varies among agents due to their different investment behaviours. 
In the HHR case (Figure 10b), the performance varies among agents with different hurdle rates. The agent with the lowest hurdle rate performs well as the index stays above 0 during the entire 80 years. The performance indexes of agents with hurdle rates from $5.25 \%$ to $6.5 \%$ per year show a different pattern. Their indexes are positive during the first 15 years, then drop to negative, and stay negative for most of the period between years 20 and 50. These agents invest in coal early on, and that turns out to be a bad investment. The indexes return to positive during the final 30 years, thanks to the profits from subsequent investments in low-carbon technologies. Agents with hurdle rates over $6.5 \%$ /year made no investments, so their indexes are 0 .

In the HF case (Figure 10c), it is helpful to divide the discussion of our results into two separate periods-before and after year 50 (when the $\mathrm{CO}_{2}$ tax stabilises). During the first period, agents that expect lower $\mathrm{CO}_{2}$ prices ( $\beta$ smaller than 0.5 ) perform poorly due to losses in coal plant investments. However, these losses are actually rather small and largely stem from the fact that these agents did not make additional investments until year 50. Meanwhile, agents with $\beta$ values between 0.6 and 1.3 either did not invest or invested in several gas plants (see Figure S4 in Supplementary Materials). During that period, agents with high $\beta$ values (i.e., $\beta=1.4$ and 1.5) had already started investing in wind, and they performed relatively well. In the second period, all agents perform equally well because after the carbon tax stabilises, agents foresee the same $\mathrm{CO}_{2}$ tax and make the same investment decisions.

One important and perhaps counterintuitive result is that the two agents that expect the highest future $\mathrm{CO}_{2}$ tax exhibit the best overall performance, even though their assumptions were incorrect. These agents invest heavily in wind, and that turns out to be profitable (see IRR in Figure 9c).

\section{Impacts of Assumptions and Simplifications}

In this section, we discuss some limitations of our model and the impact they may have on our results. We also present some additional sensitivity analysis with respect to these assumptions.

\subsection{Type of Agents}

All agents in the study are assumed to be power companies, and investments from other types of agents are not included, for example, distributed solar PV invested by households.

We have tested a case where there are "external" investments made in solar PV to resemble solar PV investments from households. We find that when significant (around $70 \mathrm{GW}$ ) exogenous PV is installed (by the households), power companies invest less in nuclear capacity, but actually more in wind and gas, compared to the case where there is no exogenous PV investment. This leads to less electricity generation from nuclear plants but more from solar, wind and gas power plants. Detailed results are presented in the Supplementary Materials, see Supplementary Section S5.3.

\subsection{Electricity Demand}

The electricity demand in this study is assumed to vary during the course of the year (seasons and day and night variations) but this demand pattern is also assumed to remain the same from one year to the other. We have tested a case where there is a $1 \%$ /year increasing demand, and find that the installed capacity of each type of technology increases compared to our base case scenario, but the overall pattern does not change. Detailed results are presented in the Supplementary Materials, see Supplementary Section S5.4.

\subsection{Size of the Plant}

Here we tested a case with a uniform plant size of $50 \mathrm{MW}$ instead of $500 \mathrm{MW}$, which is used in this study. We find that with smaller plant sizes, there are slightly more nuclear and less wind and gas capacities, but the overall result is similar to the case with $500 \mathrm{MW}$ plants. The reason why there is more nuclear is because nuclear has a rather 
high investment cost per MW, and a smaller plant size makes it possible to invest in nuclear incrementally. Detailed results are presented in the Supplementary Materials, see Supplementary Section S5.5.

\section{Conclusions}

In this paper, we have developed an agent-based model of the electricity system with heterogeneous agents. Results from this study can be useful for both modellers in the energy system community as well as scholars who investigate the low-carbon energy system transition. Results pertaining to the dynamics of the electricity system transition could also be in the interests of policy-makers.

We primarily analysed how investments in new generating capacity are affected by heterogeneity and uncertainty in terms of how agents form their capital cost (presented by the hurdle rate in this study), expectations about the future carbon price, and the competition with other agents. We then looked at how investments in the power sector change over time, and how this affects the capacity mix, electricity output, electricity prices (the average and the variability), carbon emissions and profits for the various agents.

In optimisation models, there is a central decision maker that ensures that all necessary investment decisions are made. In liberalised electricity markets, those decisions are left for the different agents to make. One interesting feature with the type of simulation model employed here is that it more closely mimics the workings of a decentralized electricity market and the fact that the system properties emerges from decisions made by individual agents that compete against one another (bottom up rather than top down). Another feature is that we may with this approach investigate how different successful companies with different investment decisions strategies eventually turn out to be and which investment decision criteria that lead to either losses or a low activity.

At the systems level, we find two distinct phases of the transition:

- The first phase takes place when wind starts to increase rapidly in response to the increasing carbon tax. This tax makes the electricity price grow, which makes investment in wind profitable. However, as the tax continues to grow, the price of electricity tends to increase most during those time periods of the year when wind output is low (because during those time periods dispatchable coal-based power generation is still used in combination with natural gas fired power plants).

- This takes us into the second phase (around the years 30-40) when changes of the profitability of future investment start to occur. During this phase it becomes more profitable to invest in technologies that can generate electricity also during time periods when wind output is low (and the electricity price is high). Thus, in this phase we see investments in nuclear, gas-fired power plants with biogas and natural gas with CCS, but also solar PV, and during this period wind capacity actually drops.

The technology mix that eventually comes to dominate the electricity system (during phase two and thereafter, see Figure $1 \mathrm{a}-\mathrm{c}$ ) depends on the characteristics of agents that make most of the investments.

In the heterogenous hurdle rate case, most investments are made by the agents with the lowest hurdle rate. One interesting dynamic here is that once these agents start to invest, electricity prices become lower (because of their lower cost of capital), and this then tends to outcompete the agents with a higher cost of capital. Furthermore, the lower hurdle rate-it turns out-leads to that nuclear becomes a much bigger player (twice as big as in the homogenous and the heterogenous forecast case, see Figure 2a). Interestingly, it also means that wind ends up playing a less important role-despite the fact that a low hurdle rate is typically considered advantageous for wind (given that wind is a capital-intensive technology). The reason for this has to do with the systems interactions that take place between nuclear, wind and gas-fired power plants (see the discussions in Section 4.1.2). Thus, one result from our paper is that the impact of the hurdle rate on the technology mix is significantly more complex than what is often thought. 
In the heterogenous forecast case, it is the agents with the highest expectation for the carbon tax that makes most investments, and that means the transition starts a bit earlier and happens at a slightly faster rate (see the discussions in Section 4.1.3.) (see Figures 2 and 10). However, it should also be observed that when the agents believe that the carbon tax will be significantly higher than it really turns out to be, they tend to overinvest in carbon neutral technologies which in turn leads to depressed electricity prices and lower profit margins (Figures 9c and 10c).

We can hence conclude that, in the present modelling effort, the heterogeneity in terms of variations in hurdle rates and tax expectations results in a "selection" of companies that dominate the investment decisions. This leads to more investments in low carbon technologies, as compared to a homogenous agents situation where all agents have a middle value in the range of possible hurdle rates and tax expectations. This in turn speeds up the transition towards lower $\mathrm{CO}_{2}$ emissions. In the case with homogeneous agents, emissions drop by more than $50 \%$ once the carbon tax reaches around $50 \mathrm{EUR} /$ ton $\mathrm{CO}_{2}$. However, when we analyse the heterogeneous cases, emissions drop much faster. When the carbon tax reaches 50 EUR / ton $\mathrm{CO}_{2}$, emissions are down by roughly $80 \%$ (see Figure 8 ).

Moreover, we have estimated the value factor for wind (i.e., the revenues received by wind per $\mathrm{kWh}$ compared to the average electricity price, see [37]) during a non-equilibrium transient phase. We find that although wind expands to significant shares of the electricity system, the absolute revenues for wind per $\mathrm{kWh}$ do not drop (which is in line with Brown and Reichenberg [39] who performed this in an equilibrium setting). However, the relative value of wind drops. The relative value decline for wind and the increasing price variations calls for policy interventions to deal with the increasing share of the variability of wind and solar. It could include state support for an expansion of the grid, expansion of storage technologies, and various demand side management strategies [46-48].

Supplementary Materials: The following are available online at: https:/ / www.mdpi.com/article/ 10.3390/en15010084/s1, Table S1: Assumed power plants parameters - costs and efficiencies; Table S2: Number of hours in each of the time slice; Table S3: Values of the demand reference, solar availability and wind availability; Table S4: Installed capacity of wind in year 80 in different set-ups in terms of hurdle rates and gas plants availability; Figure S1a-c: Annual electricity production by technologies in the (a) homogeneous case, (b) HHR case, and (c) HF case; Figure S2: The reference demand level (dashed) and the dispatched power (solid) across the time slices of the year, for four different years (years 5, 25, 40, and 80) in the homogeneous case; Figure S3: Illustration from one simulation showing the installed capacity of agents with hurdle rates from 5\%/year (top figure) to 6.75\%/year (bottom figure) in the HHR case; Figure S4: Individual agent's financial performance (measured by Performance Index) in the HHR case; Figure S5: Individual agents' installed capacity (GW) over the time period of 80 years in the HF case; Figure S6: Individual agent's financial performance (measured by Performance Index) in the HF case; Figure S7a-c: Electricity-price spread over time illustrated by 10th and 90th percentiles, as well as the average and median prices for the (a) homogeneous case, (b) HHR case, and (c) HF case; Figure S8: Standard deviation of electricity price for the homogeneous case, HHR case, and HF case; Figure S9: Annual emissions in the homogeneous case, HF case and homogeneous 10-year foresight case; Figure S10: The system installed capacity in the HHR case; Figure S11: Annual electricity production by technology in the HHR case; Figure S12: Installed capacity in the HHR case in the two demand scenarios; Figure S13: Installed capacity of individual technologies in the HHR case.

Author Contributions: Conceptualization, K.L. and C.A.; methodology, K.L. and C.A.; software, K.L and J.Y.; validation, K.L., C.A. and J.Y; formal analysis, K.L., C.A. and J.Y.; investigation, K.L., C.A. and J.Y.; writing-original draft preparation, J.Y.; writing-review and editing, K.L. and C.A.; visualization, K.L. and J.Y.; supervision, K.L. and C.A. All authors have read and agreed to the published version of the manuscript.

Funding: J.Y. received funding from ENSYSTRA (with funding through the EURpean Union's Horizon 2020 research and in-novation programme under the Marie Skłodowska-Curie grant agreement No 765515). CA and KL received funding from Carl Bennet AB, MISTRA Electrification and AFRY. 
Data Availability Statement: The model code, data and documentation are available online at https:/ / github.com/happiABM/HAPPI.

Acknowledgments: We would like to thank ENSYSTRA (with funding through the European Union's Horizon 2020 research and innovation programme under the Marie Skłodowska-Curie grant agreement No 765515), Carl Bennet AB, MISTRA Electrification and AFRY for financial support. We would also like to thank Daniel Johansson, Lina Reichenberg, Paulina Essunger, Markus Wråke, Göran Carstedt, Stefan Park, Sabine Fuss and Cookie Belfrage for valuable discussions and suggestions.

Conflicts of Interest: The authors declare no conflict of interest.

\section{References}

1. United Nations. Paris Agreement; United Nations: Paris, France, 2015; pp. 1-27.

2. Rogelj, J.; Shindell, D.; Jiang, K.; Fifita, S.; Forster, P.; Ginzburg, V.; Handa, C.; Kheshgi, H.; Kobayashi, S.; Kriegler, E.; et al. Mitigation Pathways Compatible with $1.5^{\circ} \mathrm{C}$ in the Context of Sustainable Development; Intergovernmental Panel on Climate Change: Geneva, Switzerland, 2018.

3. Johansson, D.J.A.; Azar, C.; Lehtveer, M.; Peters, G.P. The role of negative carbon emissions in reaching the Paris climate targets: The impact of target formulation in integrated assessment models. Environ. Res. Lett. 2020, 15, 124024. [CrossRef]

4. Azar, C.; Lindgren, K.; Larson, E.; Möllersten, K. Carbon Capture and Storage from Fossil Fuels and Biomass-Costs and Potential Role in Stabilizing the Atmosphere. Clim. Chang. 2006, 74, 47-79. [CrossRef]

5. Braff, W.A.; Mueller, J.M.; Trancik, J.M.M.J.E. Value of storage technologies for wind and solar energy. Nat. Clim. Chang. 2016, 6, 964-969. [CrossRef]

6. Capros, P.; Paroussos, L.; Fragkos, P.; Tsani, S.; Boitier, B.; Wagner, F.; Busch, S.; Resch, G.; Blesl, M.; Bollen, J. EURpean decarbonisation pathways under alternative technological and policy choices: A multi-model analysis. Energy Strat. Rev. 2014, 2, 231-245. [CrossRef]

7. Capros, P.; Paroussos, L.; Fragkos, P.; Tsani, S.; Boitier, B.; Wagner, F.; Busch, S.; Resch, G.; Blesl, M.; Bollen, J. Description of models and scenarios used to assess EURpean decarbonisation pathways. Energy Strat. Rev. 2014, 2, 220-230. [CrossRef]

8. Reichenberg, L.; Hedenus, F.; Odenberger, M.; Johnsson, F. The marginal system LCOE of variable renewables-Evaluating high penetration levels of wind and solar in EURpe. Energy 2018, 152, 914-924. [CrossRef]

9. Hansen, P.; Liu, X.; Morrison, G.M. Agent-based modelling and socio-technical energy transitions: A systematic literature review. Energy Res. Soc. Sci. 2019, 49, 41-52. [CrossRef]

10. Bonabeau, E. Agent-based modeling: Methods and techniques for simulating human systems. Proc. Natl. Acad. Sci. USA 2002, 99, 7280-7287. [CrossRef] [PubMed]

11. Chappin, E.J.; de Vries, L.J.; Richstein, J.C.; Bhagwat, P.; Iychettira, K.; Khan, S. Simulating climate and energy policy with agent-based modelling: The Energy Modelling Laboratory (EMLab). Environ. Model. Softw. 2017, 96, 421-431. [CrossRef]

12. Jonson, E.; Azar, C.; Lindgren, K.; Lundberg, L. Exploring the competition between variable renewable electricity and a carbonneutral baseload technology. Energy Syst. 2018, 11, 21-44. [CrossRef]

13. Kraan, O.; Kramer, G.; Nikolic, I. Investment in the future electricity system-An agent-based modelling approach. Energy 2018, 151, 569-580. [CrossRef]

14. Barazza, E.; Strachan, N. The impact of heterogeneous market players with bounded-rationality on the electricity sector lowcarbon transition. Energy Policy 2020, 138, 111274. [CrossRef]

15. Egli, F.; Steffen, B.; Schmidt, T.S. Bias in energy system models with uniform cost of capital assumption. Nat. Commun. 2019, 10, 4588. [CrossRef]

16. Hirth, L.; Steckel, J.C. The role of capital costs in decarbonizing the electricity sector. Environ. Res. Lett. 2016, 11, 114010. [CrossRef]

17. Bartlet, N.; Coleman, T.; Schmid, S. Putting a Price on Carbon-The State of Internal Carbon Pricing by Corporates Globally; CDP: Brussels, Belgium, 2021; 24p, Available online: https://cdn.cdp.net/cdp-production/cms/reports/documents/000/005/651/ original/CDP_Global_Carbon_Price_report_2021.pdf?1618938446 (accessed on 21 October 2021).

18. Trading Economics. EU Carbon Permits. 2021. Available online: https://tradingeconomics.com/commodity/carbon (accessed on 20 May 2021).

19. EURpean Commission. EU Emissions Trading System (EU ETS). 2021. Available online: https://ec.EURpa.eu/clima/eu-action/ eu-emissions-trading-system-eu-ets_en (accessed on 17 November 2021).

20. Kruger, J. Hedging an Uncertain Future: Internal Carbon Prices in the Electric Power Sector. 2017. Available online: https: //media.rff.org/documents/RFF-Rpt-Kruger-Internal20Carbon20Pricing.pdf (accessed on 17 November 2021).

21. Barradale, M.J. Investment under uncertain climate policy: A practitioners' perspective on carbon risk. Energy Policy 2014, 69, 520-535. [CrossRef]

22. Fuss, S.; Johansson, D.J.; Szolgayova, J.; Obersteiner, M. Impact of climate policy uncertainty on the adoption of electricity generating technologies. Energy Policy 2009, 37, 733-743. [CrossRef]

23. Yang, M.; Blyth, W.; Bradley, R.; Bunn, D.; Clarke, C.; Wilson, T. Evaluating the power investment options with uncertainty in climate policy. Energy Econ. 2008, 30, 1933-1950. [CrossRef]

24. Brealey, R.A.; Myers, S.C.; Allen, F. Principles of Corporate Finance, 11th ed.; McGraw-Hill Education: New York, NY, USA, 2014. 
25. Konstantin, P.; Konstantin, M. Investment Appraisal Methods. In Power and Energy Systems Engineering Economics: Best Practice Manual; Springer International Publishing: Cham, Switzerland, 2018; pp. 39-64.

26. IEA. World Energy Investment 2019; IEA: Paris, France, 2019.

27. IRENA. Renewable Power Generation Costs in 2017; International Renewable Energy Agency: Abu Dhabi, United Arab Emirates, 2018.

28. EIA. The Electricity Market Module of the National Energy Modeling System: Model Documentation 2018; U.S. Energy Information Administration: Washington, DC, USA, 2018.

29. Noothout, P.; de Jager, D.; Tesnière, L.; van Rooijen, S.; Karypidis, N.; Brückmann, R.; Jirouš, F.; Breitschop, B.; Angelopoulos, D.; Doukas, H.; et al. The Impact of Risks in Renewable Energy Investments and the Role of Smart Policies; Fraunhofer ISI: Brussels, Belgium, 2016.

30. BP, P.L.C. Statistical Review of World Energy; BP: London, UK, 2021; Available online: https:/ /www.bp.com/en/global/corporate/ energy-economics/statistical-review-of-world-energy.html (accessed on 11 October 2021).

31. Capion, K. Guest Post: Why German Coal Power is Falling Fast in 2019. 2019. Available online: https://www.carbonbrief.org/ guest-post-why-german-coal-power-is-falling-fast-in-2019 (accessed on 20 May 2021).

32. Joskow, P.L. Comparing the Costs of Intermittent and Dispatchable Electricity Generating Technologies. Am. Econ. Rev. 2011, 101, 238-241. [CrossRef]

33. Sepulveda, N.A.; Jenkins, J.D.; de Sisternes, F.J.; Lester, R.K. The Role of Firm Low-Carbon Electricity Resources in Deep Decarbonization of Power Generation. Joule 2018, 2, 2403-2420. [CrossRef]

34. Anwar, M.B.; Stephen, G.; Dalvi, S.; Frew, B.; Ericson, S.; Brown, M.; O'Malley, M. Modeling investment decisions from heterogeneous firms under imperfect information and risk in wholesale electricity markets. Appl. Energy 2022, $306,117908$. [CrossRef]

35. Royal Dutch Shell P.L.C. CDP Climate Change 2021 Information Request; Royal Dutch Shell, P.L.C.: The Hague, The Netherlands, 2021; Available online: https://www.shell.com/sustainability/transparency-and-sustainability-reporting/performance-data / greenhouse-gas-emissions.html\#vanity-aHR0cHM6Ly93d3cuc2hlbGwuY29tL2doZy5odG1s (accessed on 8 November 2021).

36. Sensfuß, F.; Ragwitz, M.; Genoese, M. The merit-order effect: A detailed analysis of the price effect of renewable electricity generation on spot market prices in Germany. Energy Policy 2008, 36, 3086-3094. [CrossRef]

37. Hirth, L. The market value of variable renewables: The effect of solar wind power variability on their relative price. Energy Econ. 2013, 38, 218-236. [CrossRef]

38. López Prol, J.; Steininger, K.W.; Zilberman, D. The cannibalization effect of wind and solar in the California wholesale electricity market. Energy Eco. 2020, 85, 104552. [CrossRef]

39. Brown, T.; Reichenberg, L. Decreasing market value of variable renewables is a result of policy. Energy Econ. 2021, 100, 105354. [CrossRef]

40. Ballester, C.; Furió, D. Effects of renewables on the stylized facts of electricity prices. Renew. Sustain. Energy Rev. 2015, 52, 1596-1609. [CrossRef]

41. Ketterer, J.C. The impact of wind power generation on the electricity price in Germany. Energy Econ. 2014, 44, 270-280. [CrossRef]

42. Woo, C.K.; Moore, J.; Schneiderman, B.; Ho, T.; Olson, A.; Alagappan, L.; Chawla, K.; Toyama, N.; Zarnikau, J. Merit-order effects of renewable energy and price divergence in California's day-ahead and real-time electricity markets. Energy Policy 2016, 92, 299-312. [CrossRef]

43. Auer, H.; Haas, R. On integrating large shares of variable renewables into the electricity system. Energy 2016, 115, 1592-1601. [CrossRef]

44. Brown, S. German State Awards EUR 317 Million To Loss-Making Coal Plants; Ember: London, UK, 2021; Available online: https:/ / ember-climate.org/commentary/2020/12/08/german-hard-coal/ (accessed on 11 October 2021).

45. Carbon Tracker Initiative. Four in Five EU Coal Plants Unprofitable as Renewables and Gas Power Ahead; Carbon Tracker Initiative: London, UK, 2019; Available online: https: / / carbontracker.org/four-in-five-eu-coal-plants-unprofitable-as-renewables-and-gaspower-ahead/ (accessed on 2 November 2021).

46. Gils, H.C. Economic potential for future demand response in Germany-Modeling approach and case study. Appl. Energy 2016, 162, 401-415. [CrossRef]

47. Göransson, L.; Johnsson, F. A comparison of variation management strategies for wind power integration in different electricity system contexts. Wind. Energy 2018, 21, 837-854. [CrossRef]

48. Schill, W.-P. Electricity Storage and the Renewable Energy Transition. Joule 2020, 4, 2059-2064. [CrossRef] 